\title{
BMJ Open Strengthening leadership as a catalyst for enhanced patient safety culture: a repeated cross-sectional experimental study
}

\author{
Solvejg Kristensen, ${ }^{1,2,3}$ Karl Bang Christensen, ${ }^{4}$ Annette Jaquet, ${ }^{3}$ \\ Carsten Møller Beck, ${ }^{3}$ Svend Sabroe, ${ }^{5}$ Paul Bartels, ${ }^{1,6}$ Jan Mainz ${ }^{3,6}$
}

To cite: Kristensen $S$, Christensen KB, Jaquet $A$, et al. Strengthening leadership as a catalyst for enhanced patient safety culture: a repeated crosssectional experimental study. BMJ Open 2016;6:e010180. doi:10.1136/bmjopen-2015010180

- Prepublication history and additional material is available. To view please visit the journal (http://dx.doi.org/ 10.1136/bmjopen-2015010180).

Received 7 January 2016 Revised 20 April 2016 Accepted 22 April 2016

CrossMark

For numbered affiliations see end of article.

Correspondence to Solvejg Kristensen; solkri@rm.dk

\section{ABSTRACT}

Objectives: Current literature emphasises that clinical leaders are in a position to enable a culture of safety, and that the safety culture is a performance mediator with the potential to influence patient outcomes. This paper aims to investigate staff's perceptions of patient safety culture in a Danish psychiatric department before and after a leadership intervention.

Methods: A repeated cross-sectional experimental study by design was applied. In 2 surveys, healthcare staff were asked about their perceptions of the patient safety culture using the 7 patient safety culture dimensions in the Safety Attitudes Questionnaire. To broaden knowledge and strengthen leadership skills, a multicomponent programme consisting of academic input, exercises, reflections and discussions, networking, and action learning was implemented among the clinical area level leaders.

Results: In total, 358 and 325 staff members participated before and after the intervention, respectively. 19 of the staff members were clinical area level leaders. In both surveys, the response rate was $>75 \%$. The proportion of frontline staff with positive attitudes improved by $\geq 5 \%$ for 5 of the 7 patient safety culture dimensions over time. 6 patient safety culture dimensions became more positive (increase in mean) $(p<0.05)$. Frontline staff became more positive on all dimensions except stress recognition $(p<0.05)$. For the leaders, the opposite was the case $(p<0.05)$. Staff leaving the department after the first measurement had rated job satisfaction lower than the staff staying on $(p<0.05)$.

Conclusions: The improvements documented in the patient safety culture are remarkable, and imply that strengthening the leadership can act as a significant catalyst for patient safety culture improvement. Further studies using a longitudinal study design are recommended to investigate the mechanism behind leadership's influence on patient safety culture, sustainability of improvements over time, and the association of change in the patient safety culture measures with change in psychiatric patient safety outcomes.

\section{Strengths and limitations of this study}

- Good acceptability of the study; response rate above $75 \%$ across survey times.

- The compliance rate of the leadership programme was high, confirming engaged leaders.

- Use of the personal identifier across survey times allowed for strong analysis; this practice is rather exceptional within patient safety culture research.

- The repeated cross-sectional study design cannot infer causality.

- The study was conducted in one department without a control group.

\section{INTRODUCTION AND OBJECTIVE}

Exposing hospital patients to risk is a universal unsolved problem; international studies have shown that $\sim 9.2 \%$ of hospitalised patients experienced adverse events, and $7.4 \%$ of these adverse events were lethal, while $43.5 \%$ were considered as preventable. ${ }^{1}$ Current literature emphasises patient safety culture (PSC) as a mediator with the potential to reduce the occurrence of adverse outcomes. $^{2-4}$ However, studies documenting effective methods to enhance PSC are sparse. $^{56}$

A culture of safety can be defined as "An integrated pattern of individual and organisational behaviour, based upon shared beliefs and values that continuously seeks to minimise patient harm, which may result from the processes of care delivery'. ${ }^{7}$ PSC is a deeperrooted aspect of the safety climate, which can be measured and improved. ${ }^{8}$ Safety climate survey outcomes constitute the sum of healthcare professionals' attitudes towards multi-dimensional aspects of patient safety, for example, teamwork, work conditions, and leadership support. ${ }^{8}$ 
In general, healthcare staff who spend more time at the bedside, and with more extensive knowledge about the safety of patients tend to be more critical of the PSC than professionals with less bedside time. ${ }^{9}{ }^{10}$ Consequently, leaders tend to have a more positive perception of the culture than frontline clinicians ${ }^{9}{ }^{11}$ and the larger this perception gap, the more errors are made at the sharp end of care. ${ }^{12}$ Therefore, it is important to identify solutions to bridge such gaps in perception.

Clinical leaders enable a culture of safety; they address and prioritise safety, and create the organisational context in which safe care can be reliably delivered. ${ }^{13} 14$ The enabling leadership activities set the frame for the clinical processes and shape frontline clinicians' attitudes towards a safety culture. ${ }^{15}$ Viewed this way, PSC can be regarded as an outcome of leadership processes with the potential to impact healthcare practices and outcomes. ${ }^{15}$ Hence, leadership is the anchor point for bridging any gaps in perceptions between the leaders and their frontline staff, thereby ensuring a safe culture at the sharp end of care. ${ }^{1617}$ To transform the services to achieve higher levels of excellence, the clinical leaders must be knowledgeable, skilled, and well trained in facilitating group communication, solving conflicts, creating motivation, development, and improvement. ${ }^{16}$ The ideal leadership training is organised in such a way that academic input, and training of skills and behaviours are embedded through a sequence of reflection, application, and experience. ${ }^{16}$ Additionally, leadership profiling and coaching can be effective means to help leaders build a safe and transparent environment for patients. ${ }^{18}$

Previous studies in which interventions characterised by strong leadership engagement have been implemented and PSC evaluated-preintervention and postintervention-have defined as their target an improvement of $10 \%$ in the proportion of staff with positive attitudes over a time period of minimum 18 months. ${ }^{19} 20$

The objectives of the present study were to investigate staff's perceptions of PSC before and after an intervention; these are intended to enhance knowledge and training skills among leaders, and to describe differences in perceptions of PSC according to status of employment and participation. The research questions were:

1. Do the proportions of frontline staff with positive attitudes towards seven PSC dimensions improve by more than $5 \%$ from before to after the intervention?

2. Do the mean scale scores of the seven PSC dimensions improve for responders participating both before and after the intervention?

3. Do the mean scale scores differ significantly between subgroups depending on status of employment and participation?

\section{METHODS}

Study design

A repeated cross-sectional experimental study design was applied; perceptions of PSC were measured before and after a leadership intervention.
Variables of interest: measures of PSC and participant demography

The Danish version of the Safety Attitudes Questionnaire (SAQ-DK) was used to survey perceptions of PSC. ${ }^{21}$ SAQ-DK has been found to be psychometrically sound. ${ }^{21}$ It is an explorative questionnaire with 31 items forming seven PSC dimensions for teamwork climate, safety climate, stress recognition, job satisfaction, perceptions of unit and department management, respectively, and working conditions. Answers are given on a 5-point Likert scale as: 1=disagree strongly, 2=disagree slightly, $3=$ neutral, 4=agree slightly, and $5=$ agree strongly. ${ }^{22}$ Items 2 and 11 are negatively worded.

Demographic information on profession, gender, organisational role, age group, work experience, and organisational affiliation was also collected in the responders' completion of the SAQ-DK.

\section{Setting}

The study took place in a psychiatric department situated at the Psychiatric Hospital of Aalborg University Hospital in the North Denmark Region. The department is one of the largest psychiatric departments in Denmark with $\sim 460$ employees, and it serves the population of the southern part of Aalborg, Denmark's fourth largest city.

The department comprises 10 outpatient and 9 inpatient specialised units; these are either open or closed units. During the study period, there were 19 clinical leaders (doctors, nurses and psychologists) at the unit level, and 2 managers at the department level.

\section{Material and data collection}

Full-time and part time staff with patient contact and working for at least half of their working time in the department qualified for inclusion in the surveys of PSC. Based on human resource data, the number of invitees was identified as 454 before, and 470 after the intervention, respectively; 19 invitees were unit level leaders at both time points.

Each participant was assigned a unique personal identifier that remained the same across the two surveys.

Before-intervention data (1st survey) were collected from 15 April to 3 May 2013; after-intervention data (2nd survey) were collected from 23 October to 13 November 2013. SAQ-DK was distributed via a unique link of emails to all included staff. Reminders were mailed to staff who had not answered after 1 week, and after 2 weeks, and the survey was closed at the end of the third week. A department-based quality improvement officer collaborated with the research team in the data collection.

\section{Leadership intervention}

To strengthen knowledge and skills among the unit level clinical leaders, a multicomponent programme consisting of academic input, exercises, reflections and discussions, networking, and action learning was 
implemented. The leadership programme intended to optimise individual leadership, upgrade leadership and quality management knowledge and skills, and ultimately bring the leaders and the department to a higher level of performance. The intervention was initiated and the overall content prespecified by the department head. However, it was designed and implemented in a dynamic way to best suit the needs of the department and the leaders, thus ensuring its relevance, motivation, and engagement. An external industrial organisational psychologist led the intervention programme.

The programme was implemented from 3 May to 1 November 2013 in five modules for a total of 9 days. The programme covered: (1) leadership as profession and as a subject, (2) situational leadership and coaching, (3) managing communication, conflicts and change, (4) motivation, development and improvement, and (5) leading groups and teams. Leader profile self-tests covering situational, change, and functional management were offered during the modules; also, a Jung-Based Type Analysis and individual supervision (up to 3 hours per leader) by the external psychologist were offered during the intervention time.

Uncommented unit-specific results from the first survey were fed back to the clinical leaders in mid-June 2013.

\section{Ethics}

As the PSC survey data were not considered as personal data, the study was neither subject to the Danish Act on Processing of Personal Data nor the Act on Research Ethics Review of Health Research Projects as the study did not involve human biological material. The department-based works council approved the study. Survey invitees were informed that: participation was voluntary; all answers would be treated with confidentiality; and no individual responses would be available to any other employee of the department. Outcomes of the leadership self-test profiles and supervision were private, and available only to the clinical leaders themselves.

\section{Statistical analyses}

The sample data were described by numbers and proportions for each of the two survey times, and for the responders participating in both surveys.

Internal scale consistency of SAQ-DK was reported by Cronbach's coefficient $\alpha,{ }^{23}$ and inter-scale correlations by Pearson's correlations coefficient.

SAQ-DK data were presented in accordance with the scoring guidelines of SAQ, reporting (1) the percentage of respondents with a positive attitude ( $\%$ positive, defined by an individual mean scale score $\geq 75$ ), and (2) scale mean scores (range $0-100$ ) and $\mathrm{SD}^{24}$ Over time, improvements in \% positive reflect an increase in the number of staff with positive attitudes, whereas improvements in the scale mean score reflect a more positive attitude among surveyed staff. Based on previous research, ${ }^{19} 20$ a $5 \%$ improvement in staff with positive attitudes towards the PSC over the two survey time points was targeted and deemed clinically relevant. If $<60 \%$ of staff report positive attitudes on any cultural dimension, improvement activities are suggested. ${ }^{24}$

Individual SAQ-DK item scores were converted to a $0-$ 100 points scale, where $1=0,2=25,3=50,4=75$ and $5=100$. Items 2 and 11 were reverse scored so that their valence matched the positively worded items.

Individual scale mean scores were calculated by the average score of the scaled items, and the $\%$ positive calculated (range $0-100) .{ }^{24}$ For each scale, $\%$ positive were compared between survey times and subgroups, using $\chi^{2}$ tests.

SAQ-DK mean scale scores were calculated for each dimension from the average score of the scaled items. Mean scale scores were compared using paired samples Student's $t$ test for the responders participating in both surveys and independent Student's t test for subgroup analysis. All analyses were performed using IBM SPSS V.21.0 (SPSS, Chicago, Illinois, USA).

\section{RESULTS}

\section{Invitees and participants}

In total, 532 staff members were invited to participate in either of the two surveys or both; 62 were only invited for the before-intervention survey as they left the department during the study period; and 392 were invited before and after the intervention. In total, 78 joined the department after the first survey and were, therefore, only invited to participate in the second survey.

After the first survey, 358 of the 454 questionnaires were returned $(78.8 \%)$, and 325 of the 470 invitees participated $(76.2 \%)$ in the second survey. Participation in both surveys (stable group) was 238 of the $392(60.7 \%)$; of the 238 in the stable group, 223 were frontline staff.

Sociodemographic respondent characteristics are shown in table 1, showing comparable characteristics across the stable group and participants in the first or second survey only, respectively.

Fifteen of the 19 leaders $(78.9 \%)$ participated in the intervention and in both PSC surveys. Of these, four were male $(26.7 \%)$; five were doctors $(33.3 \%)$; two were psychologists (13.3\%) and eight were nurses $(53.3 \%)$. All had $\geq 3$ years of experience in their profession.

The participants were classified into five groups according to their status of invitation and participation as follows:

1. Leavers: participating in the first survey, then leaving the department, $\mathrm{N}=47$

2. Dropouts: invitees in both surveys, but only participating in the first survey, $\mathrm{N}=73$

3. Stable: participants in both surveys, $\mathrm{N}=238$

4. Laggards: invitees in both surveys, but only participating in the second survey, $\mathrm{N}=31$

5. Newcomers: staff joining the department after the first survey, and participating in the second survey only, $\mathrm{N}=56$ 
Table 1 Sociodemographic characteristics of responders of the Safety Attitudes Questionnaire

\begin{tabular}{|c|c|c|c|c|c|c|}
\hline & \multicolumn{6}{|c|}{ Time of participation } \\
\hline & \multicolumn{2}{|c|}{$\begin{array}{l}\text { First survey } \\
N=358\end{array}$} & \multicolumn{2}{|c|}{$\begin{array}{l}\text { Second survey } \\
N=325\end{array}$} & \multicolumn{2}{|c|}{$\begin{array}{l}\text { First and second } \\
\text { survey } \\
\mathrm{N}=238\end{array}$} \\
\hline & $\mathbf{N}$ & Per cent & $\mathbf{N}$ & Per cent & $\mathbf{N}$ & Per cent \\
\hline \multicolumn{7}{|l|}{ Characteristics } \\
\hline \multicolumn{7}{|l|}{ Profession } \\
\hline Doctors & 43 & 12 & 36 & 11 & 23 & 10 \\
\hline Nurses & 147 & 41 & 132 & 41 & 95 & 40 \\
\hline Nursing assistants* & 74 & 21 & 67 & 21 & 49 & 21 \\
\hline Therapists $†$ & 56 & 16 & 51 & 16 & 41 & 17 \\
\hline Others $\ddagger$ & 38 & 11 & 39 & 12 & 30 & 13 \\
\hline \multicolumn{7}{|l|}{ Gender } \\
\hline Females & 290 & 81 & 267 & 82 & 192 & 81 \\
\hline Males & 68 & 19 & 58 & 18 & 46 & 19 \\
\hline \multicolumn{7}{|l|}{ Organisational role } \\
\hline Clinical leaders & 16 & 5 & 16 & 5 & 15 & 6 \\
\hline Frontline clinicians & 342 & 95 & 309 & 95 & 223 & 94 \\
\hline \multicolumn{7}{|l|}{ Age groups (year)§ } \\
\hline$<36$ & 103 & 29 & 96 & 29 & & \\
\hline$\geq 36$ to $<56$ & 203 & 57 & 181 & 56 & & \\
\hline 56 or older & 52 & 15 & 48 & 15 & & \\
\hline \multicolumn{7}{|l|}{ Work experience (year)§ } \\
\hline$<3$ & 91 & 25 & 86 & 26 & & \\
\hline 3 or more & 267 & 75 & 239 & 74 & & \\
\hline \multicolumn{7}{|l|}{ Organisational affiliation§ } \\
\hline Inpatient unit & 239 & 67 & 203 & 63 & & \\
\hline Outpatient unit & 31 & 31 & 111 & 34 & & \\
\hline No specific unit/other & 8 & 2 & 11 & 3 & & \\
\hline
\end{tabular}

The aforementioned figures for invitees are shown in the bottom row of online supplementary annex table 1a, whereas the five groups are illustrated in the second to fourth columns of the table.

\section{PSC scores over time}

SAQ-DK scores between 1 and 5 were observed for all items across both surveys. The average rate of not applicable answers at the item level was $3.0 \%$ in the first survey, and $2.6 \%$ in the second survey. Internal instrument reliability of SAQ-DK was investigated, revealing Cronbach $\alpha=0.85$ in both surveys.

At both survey times, all scales correlated negatively with the stress recognition scale, revealing weak Pearson's r correlation coefficients. For all other scales, Pearson's correlations indicated significantly moderate-to-strong positive relationships; correlation coefficients ranged from $\sim 0.25$ to 0.63 ( $\mathrm{p}<0.01$ ).

According to the definition of PSC provided above, PSC is an inclusive group-level characteristic. For that reason, the proportions of responders with positive attitudes (\% positive) are displayed graphically for all participants of the first $(\mathrm{N}=358)$ and the second survey
$(\mathrm{N}=325)$. As can be seen in figure 1 , job satisfaction was the dimension with most positive responders at both survey points and perception of department management, the dimension with least positive responders at both survey times. As such, figure 1 documents noteworthy variation in $\%$ positive across the seven dimensions at both survey times.

Figure 2 provides an overview of the proportions of stable frontline staff $(\mathrm{N}=223)$ with positive attitudes (\% positive) for the two surveys. For teamwork climate, safety climate, job satisfaction, working conditions and perception of unit management, an improvement in \% positive of $\geq 5 \%$ was observed over time. It was statistically significant for teamwork climate, safety climate and job satisfaction, $\mathrm{p}<0.01$. For teamwork climate, stress recognition and perception of unit management, a rise in $\%$ positive from $<60 \%$ in the first survey to $\geq 60 \%$ in the second survey was found. For stable frontline staff $(\mathrm{N}=223)$, the largest improvement in PSC was by $14.8 \%$ points; it was observed for safety climate, $\mathrm{p}<0.01$. In comparison, $\%$ positive for the 15 stable unit-level clinical leaders improved by $6.7 \%$ points over time, $\mathrm{p}>0.01$. In the first survey, the gap between clinical leaders and 
Figure 1 Proportions of participants with positive attitudes (\% positive) per Danish version of the Safety Attitudes

Questionnaire (SAQ-DK) dimension in the first and the second survey.

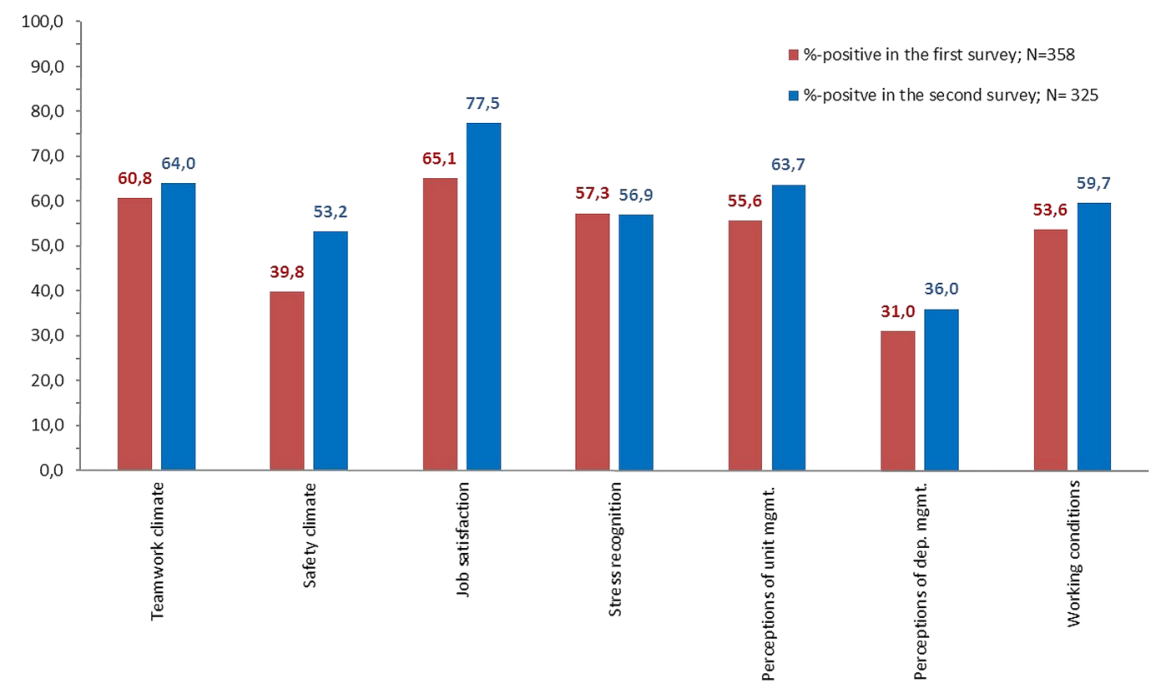

frontline staff in perception of the safety climate was $41.9 \%$ points; this gap decreased to $35.0 \%$ points in the second survey.

Mean scale results of the two surveys are shown in table 2 columns 2 and 3, respectively. Column 4 shows change in means for the stable group $(\mathrm{N}=238)$. The PSC became more positive (increase in mean) for all dimensions of the culture $(p<0.05)$, except for stress recognition. These increases ranged from 2.7 (SD 17.6) for perception of unit management to 5.4 (SD 18.7) for job satisfaction. The improvements were attributable to frontline staff $(\mathrm{N}=223)$, who increased their mean scale scores significantly for all dimensions $(p<0.05)$, except for stress recognition $(\mathrm{p}>0.05)$. In opposition to this, leaders only improved their mean scale score for stress recognition $(p<0.05)$. Changes in SAQ-DK mean scale scores over time for leaders and frontline staff, respectively, are shown in the upper half of online supplementary material annex table 2a. Equivalent results for females and males are shown in the lower half of online supplementary material annex table 2a. The gap in perception between unit level clinical leaders and frontline staff decreased for teamwork climate, safety climate, and perception of department management over time.

In both surveys, no differences in mean scale scores were found between males and females or between staff with $<3$ and $\geq 3$ years of work experience $(p>0.05)$. Online supplementary material annex table $3 \mathrm{a}$ shows a mixed picture of statistically significant and nonsignificant improvements in dimensional PSC mean scores for five professional groups.
Figure 2 Proportion of stable frontline staff ${ }^{\mathrm{a}}$ with positive attitudes (\% positive) per Danish version of the Safety Attitudes Questionnaire (SAQ-DK) dimension $(\mathrm{N}=223)$.

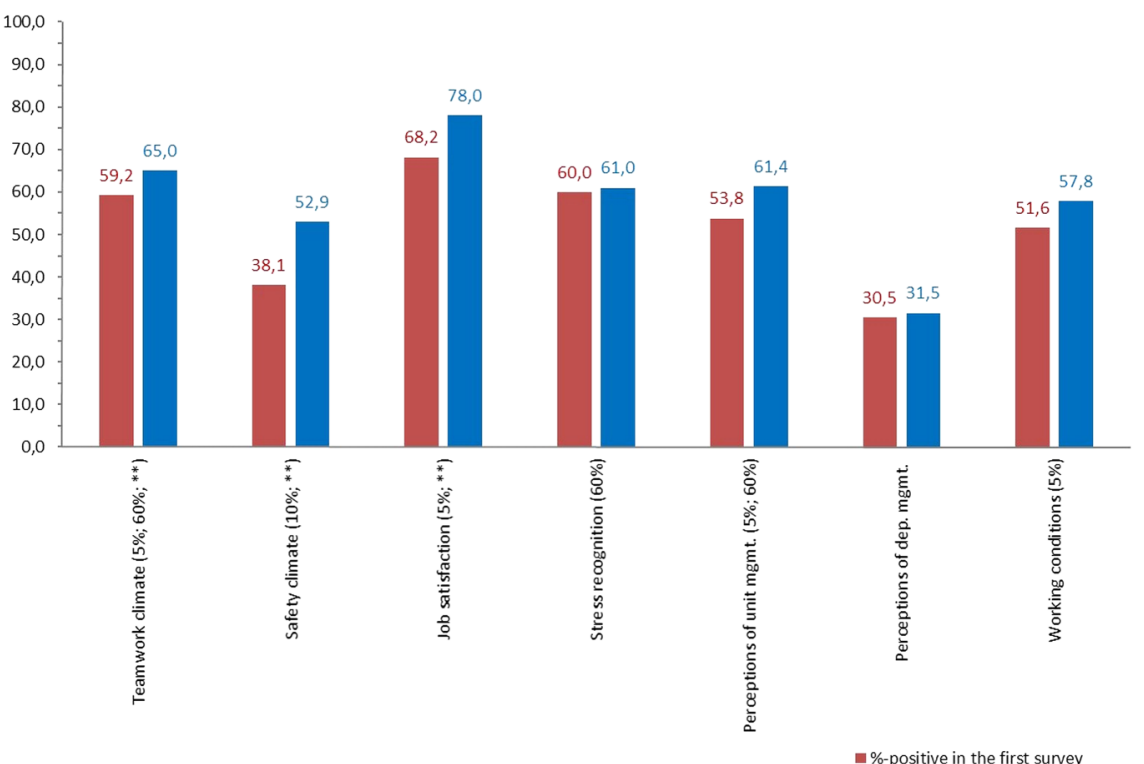

= Only frontline staff participating in both the first and the second survey

\%-positve in the second surve $5 \%$; Indicates an improvement in \%-positive $\geq 5 \%$ between the first and the second survey $10 \%$; Indicates an improvement in \%-positive $\geq 10 \%$ between the first and the second surve $60 \%$; Indicates a rise in \%-positive from $<60 \%$ before to $\geq 60 \%$ after the intervent 
Table 2 Mean scale results for Danish version of the Safety Attitudes Questionnaire (SAQ-DK) in the first and in the second survey, and the mean difference for the stable group

\begin{tabular}{|c|c|c|c|}
\hline Dimension & $\begin{array}{l}\text { First survey } \\
\mathrm{N}=358 \\
\text { Mean (SD) }\end{array}$ & $\begin{array}{l}\text { Second survey } \\
\mathrm{N}=325 \\
\text { Mean (SD) }\end{array}$ & $\begin{array}{l}\text { Mean difference over time } \\
\mathrm{N}=238 \\
\text { Mean difference (SD); } \\
\text { significance* }^{*}\end{array}$ \\
\hline Teamwork climate & 74.7 (17.9) & $77.6(17.0)$ & $3.1(17.4) \dagger$ \\
\hline Safety climate & $68.0(18.3)$ & $72.1(18.5)$ & $4.8(17.7) \dagger$ \\
\hline Job satisfaction & 75.7 (19.3) & $82.2(17.9)$ & $5.4(18.7) \dagger$ \\
\hline Stress recognition & $70.0(22.9)$ & $70.3(22.9)$ & $0.6(19.6)$ \\
\hline Perceptions of unit management & $70.4(22.3)$ & $76.5(18.1)$ & $5.3(20.2) \dagger$ \\
\hline Perceptions of department management & $62.3(19.7)$ & $65.4(18.6)$ & $2.7(17.6) \ddagger$ \\
\hline Working conditions & $69.8(23.6)$ & $72.7(23.7)$ & $3.4(22.5) \ddagger$ \\
\hline
\end{tabular}

For the stable group ( $\mathrm{N}=238)$, both the proportion of responders with positive attitudes (\% positive) and their perceptions of the PSC (mean scale score) improved significantly $(\mathrm{p}<0.05)$ for safety climate and job satisfaction. These results are shown in table 3 columns 4 and 5 , rows 4 and 5 .

\section{Differences in perception of culture according to status of participation}

PSC is a group level characteristic, and when conducting PSC before and after the measurements, it is customary to report and compare $\%$ positive and/or mean scales scores for the population taking part at each of the two assessment times. In practice, a group of staff is dynamic over time; staff are leaving and coming, and it cannot be ruled out that staff attitudes are related to the status of employment and choice of participation, for example, leavers and dropouts might be more negative in their perception than the stable group of staff. Likewise, laggards and newcomers might have safety culture perceptions different from the stable group. The unique personal identifier applied in this study allowed us to describe and compare SAQ-DK mean scores for the five subgroups aforementioned.

Three groups participated in the first survey: leavers $(\mathrm{N}=47)$, dropouts $(\mathrm{N}=73)$ and stable staff $(\mathrm{N}=238)$. Among the three groups and across all seven dimensions, leavers were characterised by least $\%$ positive. The difference was statistically significant for job satisfaction $\left(\chi^{2}=5.28, \mathrm{df}=1, \mathrm{p}=0.02\right)$ only. For all PSC dimensions, the mean scale score of the leavers was lowest, but again the difference in means was only significant for job satisfaction $(\mathrm{F}=5.31, \mathrm{df}=2, \mathrm{p}<0.01)$. No differences in means were found between the dropouts and staff in the stable group for any dimension, $(p>0.05)$. All these results are shown in table 3 columns $2-4$.

The three groups only participating in the second survey were: stable staff $(\mathrm{N}=238)$, laggards $(\mathrm{N}=31)$, and newcomers $(\mathrm{N}=56)$. No specific patterns were observed concerning the mean and the $\%$ positive among the three groups after the intervention; results are shown in table 3 columns $5-7$.

\section{DISCUSSION}

This is the first intervention study within Danish psychiatry to report before-intervention and after-intervention measures of PSC, and the study adds to the sparse international literature on enhancing PSC. ${ }^{5}{ }^{6}$ The principal findings document improvements of $\geq 5 \%$ for frontline staff with positive attitudes towards teamwork climate, safety climate, job satisfaction, perception of unit management, and working conditions. For the first three of these dimensions, the improvements were significant. The largest improvement was found for stable frontline staff with regard to safety climate. Further, the PSC was rated more positively over time for all dimensions, except for stress recognition. For the stable group of clinical leaders and frontline staff participating in both surveys, the proportion of responders with positive attitudes as well as the degree of positive PSC perceptions improved significantly for safety climate and job satisfaction.

\section{Strengths and weaknesses of the study}

Both the high response rate (which was above $75 \%$ across survey times), the low average rate of not applicable answers at the item level, and the internal reliability of SAQ-DK were good, and comparable to previous Danish and international findings. ${ }^{21} 2225$ These issues underpin the acceptability of the study and support good internal validity of the study.

The use of the personal identifier across survey times enabled strong analysis of the before-data and after-data as well as subgroup analysis according to the organisational role, status of employment, and participation. This practice is rather exceptional within PSC research; it allows for a degree of transparency and subgroup analyses we have not found in other literature. 


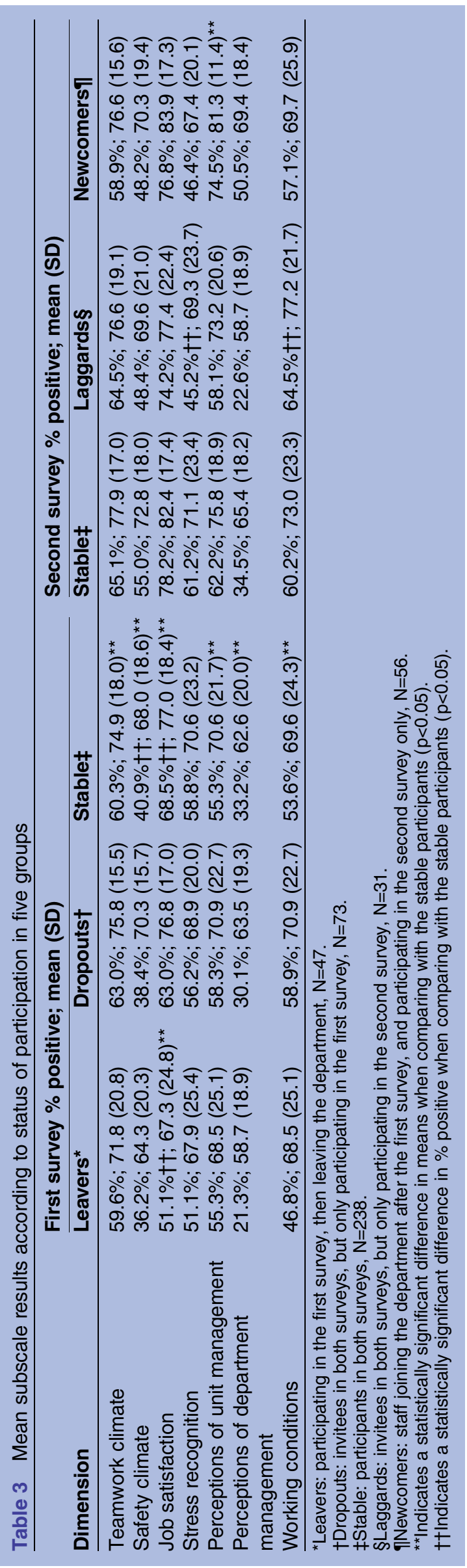

The leadership intervention was intensive, and dynamically designed and implemented specifically to match the needs of the individual leaders and the department. The rate of compliance with the leadership programme was high, confirming engaged leaders.

In terms of study weaknesses, the repeated crosssectional study design cannot infer causality. Moreover, the study was conducted in one department only without a control group, which reduces the ability to attribute causality for the improvements observed in PSC dimensions. Further, the study design can only give an insight into the PSC at the time of the survey. Also, it should be taken into account that other simultaneous initiatives and context factors might have influenced the results besides the intervention. Such possible influences were sought to be minimised by the short observation period. However, the short observation period did not take into account the fact that the full effect of the intervention might not be immediate; achieving sustainable change in the PSC is a long-term process. Hence, it is possible that the ongoing long-term surveillance of the PSC in the department could reveal other results. In addition, the study was based on self-reported PSC, which might have created information, recall, and social desirability bias. Lastly, the Hawthorne effect cannot be ruled out; improvements in PSC might be attributable to staff's awareness of being observed.

\section{Relation of the findings to other studies}

A number of controlled before and after studies in which the intervention contained a substantial amount of leadership engagement have found varying levels of improvement in $\%$ positive, primarily in teamwork and safety climate. ${ }^{5}$ These studies differ from ours in that they rely on patient safety intervention programmes primarily aiming to reduce adverse patient outcomes. ${ }^{562627}$ These use generic intervention methods such as executive walk rounds and the Comprehensive Unit-based Safety Programme. ${ }^{5} 62627$ The difference in findings between these studies and ours might be explained by multiple factors: our study addressed knowledge and training of the skills of leaders directly; the content of our intervention was specifically tailored to local needs, and it covered the generic aspects of leadership and quality management. The direct aim of our programme was to strengthen the individual leader, align skills and ways of doing things. The indirect aim was to bring the organisation to a higher level of performance. The aforementioned differences between our intervention and other standardised programmes must be considered when interpreting and generalising the findings of this study.

Most intervention studies have been carried out in a somatic setting, ${ }^{562627}$ and it seems fair to assume that PSC might differ across somatic and psychiatric hospitals as tasks and practices differ with different patient populations and needs. However, previous Danish research only found a difference in means for stress recognition. ${ }^{21}$ So 
the leadership approach in our intervention could also be effective in Danish somatic hospitals.

Our intervention worked well for improving the PSC in the setting it was designed for, but we did not collect clinical outcome data which could have shed some light on the ultimate question regarding the association between the PSC and the quality of the clinical performance. Other studies from somatic hospital care have shown simultaneous improvements in PSC and specific patient outcomes such as infections, mortality, and length of stay. ${ }^{562627}$

Large variations in \% positive were observed across dimensions at both survey times. This is consistent with findings in the literature ${ }^{22} 28-32$ and underlines the importance of viewing PSC as a multidimensional concept. It also indicates that the dimensions differ in their sensitivity to influential factors over time.

Since we applied the unique personal identifier, we could perform analysis of subgroups related to organisational role, status of employment, and participation. We have not been able to find comparable analyses and results in the literature.

Our findings regarding leavers and stable staff imply that the PSC results obtained after an intervention, and described in the literature might be slightly overestimated if they rely on comparison of ratings of the before the intervention population with the rating of after the intervention without allowing for shift in staff. This problem seems most vital for job satisfaction. The findings regarding job satisfaction for staff leaving the department after the first survey imply that leaders should initiate indepth analysis of low ratings for job satisfaction to learn why these are low.

Clinical leadership is a complex and demanding task which requires leaders to act as role models for frontline staff, provide inspiring visions, foster behavioural change as well as manage implementation of change. Uptake and spread of change are facilitated through close cooperation between leaders and frontline staff. ${ }^{33}$ Thus, clinical leaders are often the ones who opt for improvement, but it is the frontline staff who are expected to live out the changes. Consequently, change in behaviour and attitudes among leaders could be expected to be a lever for change among frontline clinicians. Frontline clinicians reported significant improvements (mean scores) in all dimensions of the culture, except stress recognition. By contrast, the leaders only significantly improved their attitudes towards stress recognition. The leaders were exposed to a substantial amount of new knowledge and exercises, which may have made them more realistic or critical in their assessment of the PSC, possibly affecting the leader-frontline gap in perception of safety climate-the dimension directly related to the clinical work and clinical risk management. Safety climate reflects the sum of healthcare staff's perceptions and attitudes towards the safety of patients. ${ }^{34}$

It has been suggested that units with $<60 \%$ positive responders have the most to gain in PSC from quality improvement initiatives. ${ }^{30}$ Our study only found a rise in $\%$ positive from $<60 \%$ before the intervention to $\geq 60 \%$ after the intervention for teamwork climate, and the improvement was $\geq 5 \%$ and statistically significant. Teamwork climate embraces the perceptions of healthcare staff for working together collaboratively to provide safe care for the patients. ${ }^{34}$ It seems likely that teamwork climate was directly influenced by the leadership intervention.

A cross-European study in air traffic management indicates that safety culture is more positive in Northern Europe in comparison to the rest of the EU. ${ }^{35}$ Our findings in a psychiatric hospital context point in this direction too; mean scale scores as well as $\%$ positive were comparable to findings from Sweden, but somewhat higher than in the UK, Switzerland, Taiwan and Australia. ${ }^{22} 28-32$ In addition, the subgroup analysis of differences in mean scale scores (from 1st to 2nd survey) revealed a pattern rather different to the findings in the literature, ${ }^{36} 37$ as no statistical differences in the quality of the PSC were found between gender and the two groups of seniority. According to findings in the literature, bedside staff, females and inexperienced staff were expected to be more critical than their respective counterparts. $^{9}{ }^{10}$ The study results can only point to what and not answer why; however, a possible explanation might have something to do with the underlying national cultural traits of the Danish society. Globally, the Nordic countries are the ones with most social trust. ${ }^{38}$ Organisational culture develops from national cultural traits, ${ }^{35}$ and PSC can be seen as a subset of organisational culture. ${ }^{39}$ Thus, social trust might be an underlying factor that could explain why our findings differ from the ones reported in the international literature.

\section{Study implications}

Leadership knowledge and skills seem to be pivotal to improving the PSC. Consequently, leaders need to acknowledge their role in building a safe and caring culture, they need to understand the nature of the safety culture in their unit, and recognise when and how improvement is necessary. Exceptional improvements in PSC are possible when intervention programmes are tailored to the local needs in terms of content and ways of learning.

On the basis of the results of the subgroup analyses related to status of employment and participation, it is recommended that leaders direct their attention to low ratings of job satisfaction, uncover the reasons for it, and act accordingly.

\section{CONCLUSIONS}

The results imply that strengthening leadership can act as a significant catalyst for both improvements in the proportions of staff with positive attitudes and a more positive culture. Although the PSC improvements 
observed are remarkable, a longitudinal study design is recommended to investigate the mechanism behind leadership's influence on PSC sustainability of improvements over time, and the association of change in the PSC measures with change in psychiatric patient safety outcomes.

\section{Author affiliations}

${ }^{1}$ The Danish Clinical Registries, Aarhus, Denmark

${ }^{2}$ Department of Health Science and Technology, Aalborg University, Aalborg, Denmark

${ }^{3}$ Aalborg University Hospital—Psychiatric Hospital, Aalborg, Denmark ${ }^{4}$ Department of Biostatics, University of Copenhagen, Copenhagen, Denmark ${ }^{5}$ Department of Public Health, Aarhus University, Aarhus, Denmark

${ }^{6}$ Department of Clinical Medicine, Aalborg University, Aalborg, Denmark

Acknowledgements The authors would like to thank the study participants for their effort and support.

Contributors SK led the work concerning conception and design, implementation of the Safety Attitudes Questionnaire, analysis, interpretation of data and reporting. KBC contributed to the data analysis and interpretation of results. AJ and CMB conceptualised the leadership intervention and initiated implementation. AJ contributed to implementation of the Safety Attitudes Questionnaire. SS, PB and JM contributed to the conception and the design of the study and interpretation of data. The first author (SK) led the work writing the manuscript, she drafted the manuscript and revised it upon comments from the other authors. All authors approved the final manuscript, and all are accountable for its content.

Funding This work was supported by the TrygFonden (ID 103696), Denmark and by Aalborg University Hospital-Psychiatric Hospital, Aalborg, Denmark.

Competing interests $\mathrm{AJ}, \mathrm{CMB}$, and JM are employed at Aalborg University Hospital-Psychiatric Hospital, Aalborg, Denmark.

Ethics approval The institutional work council.

Provenance and peer review Not commissioned; externally peer reviewed.

Data sharing statement No additional data are available.

Open Access This is an Open Access article distributed in accordance with the Creative Commons Attribution Non Commercial (CC BY-NC 4.0) license, which permits others to distribute, remix, adapt, build upon this work noncommercially, and license their derivative works on different terms, provided the original work is properly cited and the use is non-commercial. See: http:// creativecommons.org/licenses/by-nc/4.0/

\section{REFERENCES}

1. de Vries EN, Ramrattan MA, Smorenburg SM, et al. The incidence and nature of in-hospital adverse events: a systematic review. Qual Saf Health Care 2008;17:216-23.

2. McFadden KL, Stock GN, Gowen CR 3rd. Leadership, safety climate, and continuous quality improvement: impact on process quality and patient safety. Health Care Manage Rev 2015;40:24-34.

3. Nieva VF, Sorra J. Safety culture assessment: a tool for improving patient safety in healthcare organizations. Qual Saf Health Care 2003;12(Suppl 2):ii17-23.

4. Taylor SL, Dy S, Foy R, et al. What context features might be important determinants of the effectiveness of patient safety practice interventions? BMJ Qual Saf 2011;20:611-17.

5. Morello RT, Lowthian JA, Barker AL, et al. Strategies for improving patient safety culture in hospitals: a systematic review. BMJ Qual Saf 2012;22:11-18.

6. Weaver SJ, Lubomksi LH, Wilson RF, et al. Promoting a culture of safety as a patient safety strategy: a systematic review. Ann Intern Med 2013;158(Pt 2):369-74.

7. Kristensen S, Mainz J, Bartels P. Patient Safety. A vocabulary for European application. Aarhus: Sun-Tryk Aarhus University, 2007. http://www.hope.be/03activities/docsactivities/SIMPATIE_Patient safety_vocabulary_Professionals.pdf
8. Colla JB, Bracken AC, Kinney LM, et al. Measuring patient safety climate: a review of surveys. Qual Saf Health Care 2005;14:364-6.

9. Singer SJ, Falwell A, Gaba DM, et al. Patient safety climate in US hospitals: variation by management level. Med Care 2008;46:1149-56

10. Singer SJ, Gaba DM, Falwell A, et al. Patient safety climate in 92 US hospitals: differences by work area and discipline. Med Care 2009;47:23-31.

11. Pronovost PJ, Weast B, Holzmueller CG, et al. Evaluation of the culture of safety: survey of clinicians and managers in an academic medical center. Qual Saf Health Care 2003;12:405-10.

12. Firth-Cozens J, Mowbray D. Leadership and the quality of care. Qual Health Care 2001;10(Suppl 2):ii3-7.

13. Vogus TJ, Weick KE, Sutcliffe KM. Doing no harm: enabling, enacting, and elaborating a culture of safety in health care. Acad Manag Perspect 2010;24:60-77.

14. Kanerva A, Lammintakanen J, Kivinen T. Patient safety in psychiatric inpatient care: a literature review. J Psychiatr Ment Health Nurs 2013;20:541-8.

15. Brand CA, Barker AL, Morello RT, et al. A review of hospital characteristics associated with improved performance. Int J Qual Health Care 2012;24:483-94.

16. Swanwick T, McKimm J, eds. ABC of Clinical Leadership. Chichester, UK: BMJ Books, Blackwell Publishing Ltd, 2010.

17. Dixon-Woods M, Baker R, Charles K, et al. Culture and behaviour in the English National Health Service: overview of lessons from a large multimethod study. BMJ Qual Saf 2014;23:106-15.

18. Nelson E, Hogan R. Coaching on the dark side. Int Coaching Psychol Rev 2009;4:9-21.

19. Pronovost PJ, Berenholtz SM, Goeschel CA, et al. Creating high reliability in health care organizations. Health Serv Res 2006;41(4 Pt 2):1599-617.

20. Frankel A, Grillo SP, Pittman M, et al. Revealing and resolving patient safety defects: the impact of leadership WalkRounds on frontline caregiver assessments of patient safety. Health Serv Res 2008;43:2050-66.

21. Kristensen $\mathrm{S}$, Sabroe $\mathrm{S}$, Bartels $\mathrm{P}$, et al. Adaption and validation of the Safety Attitude Questionnaire for the Danish hospital setting. Clin Epidemiol 2015;7:149-60.

22. Sexton JB, Helmreich RL, Neilands TB, et al. The Safety Attitudes Questionnaire: psychometric properties, benchmarking data, and emerging research. BMC Health Serv Res 2006;6:44.

23. Cronbach LJ. Coefficient alpha and the internal structure of tests Psychometrika 1951;16:297-334.

24. Scale Computation Instructions. The University of Texas at Houston - Memorial Hermann Center for Healthcare Quality and Safety. Ref Type: Internet Communication. 2015. https://med.uth.edu/chqs/files/ 2012/05/SAQ-Short-Form-Scale-Items 000.pdf [homepage on the Internet] (accessed 29 Sept 2015).

25. Burstrom L, Letterstal A, Engstrom ML, et al. The patient safety culture as perceived by staff at two different emergency departments before and after introducing a flow-oriented working model with team triage and lean principles: a repeated cross-sectional study. BMC Health Serv Res 2014;14:296.

26. Singer SJ, Vogus TJ. Reducing hospital errors: interventions that build safety culture. Annu Rev Public Health 2013;34:373-96.

27. Hale AR, Guldenmund F, van Loenhout PLCH, et al. Evaluating safety management and culture interventions to improve safety: effective intervention strategies. Saf Sci 2010;48:1046-35.

28. Chaboyer W, Chamberlain D, Hewson-Conroy $\mathrm{K}$, et al. CNE article: safety culture in Australian intensive care units: establishing a baseline for quality improvement. Am J Crit Care 2013;22: 93-102.

29. Lee WC, Wung HY, Liao HH, et al. Hospital safety culture in Taiwan: a nationwide survey using Chinese version Safety Attitude Questionnaire. BMC Health Serv Res 2010;10:234.

30. Norden-Hagg A, Sexton JB, Kalvemark-Sporrong S, et al. Assessing safety culture in pharmacies: the psychometric validation of the Safety Attitudes Questionnaire (SAQ) in a national sample of community pharmacies in Sweden. BMC Clin Pharmacol 2010;10:8

31. Pronovost PJ, Berenholtz SM, Goeschel C, et al. Improving patient safety in intensive care units in Michigan. $J$ Crit Care 2008;23:207-21.

32. Schwendimann R, Zimmermann N, Kung K, et al. Variation in safety culture dimensions within and between US and Swiss Hospital Units: an exploratory study. BMJ Qual Saf 2013;22:32-41.

33. Braithwaite J, Marks D, Taylor N. Harnessing implementation science to improve care quality and patient safety: a systematic review of targeted literature. Int J Qual Health Care 2014;26: 321-9. 
34. Rose JS, Thomas CS, Tersigni A, et al. A leadership framework for culture change in health care. Jt Comm J Qual Patient Saf 2006;32:433-42.

35. Reader TW, Noort MC, Shorrock S, et al. Safety sans Frontieres: an international safety culture model. Risk Anal 2015;35:770-89.

36. Bondevik GT, Hofoss D, Hansen EH, et al. Patient safety culture in Norwegian primary care: a study in out-of-hours casualty clinics and GP practices. Scand J Prim Health Care 2014;32:132-8.
37. Gallego B, Westbrook MT, Dunn AG, et al. Investigating patient safety culture across a health system: multilevel modelling of differences associated with service types and staff demographics. Int J Qual Health Care 2012;24:311-20.

38. Bjoernskov C. Determinants of generalized trust: a cross-country comparison. Public Choice 2006;130:1-21.

39. Speroff T, Nwosu S, Greevy R, et al. Organisational culture: variation across hospitals and connection to patient safety climate. Qual Saf Health Care 2010;19:592-6. 